\title{
CONDIÇÕES SÓCIO ESTRUTURAIS DA PRODUÇÃO RURAL NO BRASIL
}

\author{
Fernando Cardoso Pedrão
}

\section{RESUMO}

As condições históricas concretas da produção rural mudam junto com as modificações do sistema capitalista de produção, em novos modos de articulação com o sistema financeiro e os sistemas de comercialização. No Brasil a produção rural desenvolveu-se sobre formas tradicionais de dominação. O avanço de grandes capitais significou valorização do capital e desvalorização do trabalho. Torna-se necessário atualizar a análise da produção rural para entender seu papel na nova reprimarização da economia nacional.

Palavras-chave: articulação comercial, produção rural, retrocesso estrutural.

\section{STRUCTURAL CONDITIONS OF RURAL PRODUCTION IN BRAZIL}

\begin{abstract}
Historical conditions of rural production change along with the capitalistic system as a whole, with financial and commerce conditions. In Brazil, rural production evolved from extreme exploitation of slavery and traditional forms of domination in general. The expansion of big capital in rural environment meant valuation of capital and devaluation of work. It's imperative now to renew the analysis of rural production to understand its role in the ongoing coming back to primary economy.
\end{abstract}

Keywords: commercial linking, rural production, structural backwardness.

\section{PRELIMINARES}

$\mathrm{Na}$ economia mundializada de hoje, a produção rural tem um papel diferente do que teve durante a segunda revolução industrial, que no Brasil se estendeu até a década de 1980. Ao contrário da visão industrialista prevalecente no após guerra, não há desenvolvimento sem desenvolvimento rural e não há agricultura satisfatória sem soluções sensíveis dos problemas agrários. A visão industrialista do desenvolvimento foi uma simplificação que desconheceu os fundamentos rurais da indústria e da urbanização, que aumentaram a demanda mundial de produtos rurais (ABRAMOVAY, 1998). Essa mudança aconteceu com diferentes formas e intensidades desde a China à Suíça, surgindo novas

${ }^{1}$ Graduado em Economia (UFBA). Doutorado em Economia (UFBA). Livre Docência (UFBA). Diretor acadêmico do Instituto Brasileiro de Políticas Sociais e Econômicas. E-mail: fernandopedrao@gmail.com. 
especializações e novos requisitos de qualidade. Por exemplo, os Estados Unidos e - Canadá surgem como produtores de queijos copiados dos franceses, a Argentina e o Uruguai passaram a produzir vinhos de qualidade, amplia-se o espaço da pequena produção europeia de alto nível. Resultados ligados a qualificação do trabalho e organização comercial.

No Brasil a produção rural atravessa um período de transformação estrutural, forçado por sua inserção no mercado mundial e por pressões internas de valorização do capital e desvalorização do trabalho. Um modo de capitalismo centralizador e mais violento que em outras partes do continente. Combina movimentos de expansão de investimentos de grande capital com bloqueio e estagnação da pequena produção, destituída de apoio público real, constrangida por sistemas de comercialização de grande capital, por supermercados e redes internacionais de cerealistas. Desde a década de 1970 incorporaram-se mais de 200 milhões de hectares à superfície dos estabelecimentos agropecuários, um dado que encobre a expansão de grandes propriedades absenteístas. Aumentou a proporção de terras novas por oposição aos sistemas tradicionais, desvalorizando terras dos sistemas anteriores, desempregando as populações de caboclos, mestiços e negros, os caipiras e tabaréus. Abriram-se condições de fronteira agrícola para grandes capitais absenteístas, que deram lugar a migração de capitais das diversas regiões do país para o oeste, tanto do Sudeste como do Nordeste. Altera-se a composição de usos de capital e trabalho na produção rural e relega-se a segundo plano a qualificação do trabalho junto com a extinção de emprego regular.

Sob os efeitos de rápida e extensa monoculturização, e de expansão da produção da pecuária, o componente rural da produção tornou-se estratégico como gerador de exportações e ofertante de matérias primas para a urbanização. Ao lado da oferta de alimentos, conta-se a de materiais de construção, madeira e materiais de cerâmica. Os rumos da formação de capital e da geração de emprego na produção rural passaram a ser determinados por fatores externos ao setor, como a demanda internacional e a demanda interna de matérias primas. Mas o aumento da formação de capital no setor correspondeu a vertiginosa queda do emprego junto com a mecanização, com formas precárias de ocupação, resultando em migração para as cidades, favelização de pequenas cidades e povoados. Generaliza-se a violência no meio rural com um crime modernizado que modifica o padrão territorial do povoamento (AMIN, 1977).

O novo crescimento da produção rural afirma-se como principal traço da reprimarização da economia brasileira, na qual o sistema em seu conjunto depende de exportações primárias na produção rural e na mineração ${ }^{2}$. Esse aumento da importância da produção rural tem efeitos políticos, econômicos e sociais, fortalecendo o poder político dos capitais do setor e induzindo uma queda brusca do efeito emprego dos investimentos. Delineia-se uma contradição entre o papel estratégico da produção rural e o modo como ela é tratada na política econômica nacional, em que ela é representada pelos interesses dos ruralistas. Dadas as diferenças entre os interesses de empresas e produtores, impõe-se rever o relativo à

\footnotetext{
${ }^{2} U m$ estudo colateral terá que ser feito sobre a produção mineral, hoje basicamente realizada por grandes capitais, onde a maior parte do emprego acontece em garimpos. Desde o período colonial o Brasil foi um exportador de minerais produzidos em forma artesanal, primeiro de minérios preciosos e depois de matérias primas industriais. Desde a Segunda Guerra Mundial o Brasil veio a ser exportador controlado por interesses do bloco saxônico. Observe-se que até hoje grande parte da produção de mármores e granitos é realizada por um mecanismo de grande artesanato. A mineração de materiais industriais, ferro, manganês e outros agora nióbio e vanádio - é realizada por capitais internacionais com pequena margem de beneficiamento no país.
} 
produção rural em sua atual organicidade e significado social e em sua inserção no mercado internacional e no interno.

\section{ANTECEDENTES (IN)VÁLIDOS}

As teorias do desenvolvimento surgidas após a Segunda Guerra Mundial, que prevaleceram praticamente até o fim da década de 1980, aceitaram como inquestionáveis dogmas da industrialização pelos quais (a) se trabalha com setores separados uns dos outros, (b) a indústria lidera o progresso técnico do sistema, com diferenciais crescentes de produtividade, (c) a agricultura representa o componente de produção tradicional do sistema; (d) há uma correlação positiva direta entre investimento e emprego, pelo que o efeito multiplicador do sistema se concentra na indústria. Ignorou-se o crescimento dos serviços em geral em que os serviços a empresas tornaram-se a grande mídia a serviço do capital, convertida em controle do consumo, com inquestionável influência no sistema político.

Esse modelo inaugurado por Colin Clark (1949) supõe diferenças insuperáveis na absorção de tecnologia, assim como condições invariantes de financiamento. Esse modelo de análise, macroeconômica de base keynesiana, foi absorvido pelas Nações Unidas e constituiu a base dos estudos de desenvolvimento da América Latina ${ }^{3}$. É um modelo com graves limitações, que adiante valeram críticas aos trabalhos da CEPAL por ignorarem as inter-relações estruturais nos movimentos de substituição das tecnologias principais. Por exemplo, os efeitos sistêmicos da substituição de aviões a hélice por aviões a turbina. Desconhece os progressos tecnológicos da produção rural e do comércio. Ignora os efeitos da expansão do setor improdutivo da economia, acusado por Paul Baran (1959).

A simplificação falaciosa desse modelo permitiu que se tomasse como base a composição setorial da macroeconomia keynesiana, identificando a composição das contas nacionais com a do sistema de produção. Confundiram-se alterações na composição do produto social com transformações concretas dos sistemas produtivos nacionais, que correspondem a condições específicas de participação no mercado mundial. Uma elevação fortuita da produção de cereais por conta de hidrometria não permite explicar diferenças de controle biológico da produção. Paralelamente, elevações da produção industrial promovidas por transferências de algumas empresas não garante continuidade desse movimento nem que essas empresas migrem para terceiras localizações ${ }^{4}$. Assim, também, a uma análise superficial da indústria pode parecer que a indústria nas economias periféricas se desenvolve sobre bases setoriais sem o benefício de relações Inter setoriais ${ }^{5}$. Nesse modelo simplificador deixaram de ser consideradas as inter-relações entre as atividades das indústrias de transformação e as da produção rural, reduzidas ao título simbólico de agricultura. Essa análise simplificadora seria aceita pelas correntes de pensamento derivadas do marginalismo, sejam elas neoclássicas ou keynesianas ${ }^{6}$. Na prática, a teoria econômica mantinha duas falácias que seriam as

\footnotetext{
${ }^{3} \mathrm{O}$ principal exemplo é a série de estudos de economias nacionais realizado pela CEPAL nas décadas de 1950 e 1960 com o título geral de Análise e Projeções do Desenvolvimento Econômico, que incluiu trabalhos sobre Argentina, Bolívia, Brasil, Colômbia, México, Peru. Esses trabalhos foram a base dos trabalhos de planejamento daquele período. Destacam-se, também, estudos de economia agrícola que tiveram influência em linhas de trabalho da FAO e em universidades chilenas e brasileiras que deslocaram o foco das condições sócio estruturais para as condições sociais do progresso técnico. Sutilmente, olhar a produção rural na perspectiva do capital.

${ }_{5}^{4} \mathrm{O}$ caso emblemático da Ford no Brasil.

${ }^{5}$ Oportuno lembrar o trabalho marco de milha de Hollis Chenery sobre Desenvolvimento econômico e transformações estruturais (1977).

6 Ver meu trabalho Refutação ao marginalismo (PEDRÃO, 2014).
} 
de: a) aceitar o paradigma de separação entre setores como algo determinado para o sistema produtivo em seu conjunto e b) de reduzir a produção rural às formas técnicas da agricultura, que de fato não existem desde a revolução industrial.

A falácia se agravou desde o salto da industrialização, que no essencial significou a substituição da produção bélica por uma reorganização da produção para consumo e focalizou na intensificação do uso da capacidade industrial. Foi um movimento liderado pelos Estados Unidos, apoiado pela expansão do capital financeiro que a União Soviética não acompanhou, e funcionou como plataforma para a recuperação da economia japonesa. Nessa nova etapa do capitalismo, que sustentou uma rápida urbanização, a produção rural passava a ter posição estratégica, primeiro para abastecer a população urbana e segundo para prover matérias primas para a industrialização e para a urbanização. Matérias primas para a construção civil e para o crescente setor de embalagens. A produção direta de alimentos mostra limitações para mecanização e monoculturização, fazendo com que os grandes capitais prefiram monoculturas de matérias primas e pecuária a lavouras, com interesse restrito a alimentos de consumo de massa.

$\mathrm{O}$ avanço do sistema se deu pela ligação entre comércio e capital financeiro, que impulsionou o mercado de produtos rurais industrializados. Longe da premissa anterior de separação entre setores, são novas composições internacionais de investimentos que dão os rumos do mercado. Desde a década de 1960 as grandes empresas se tornam multipropósitos e multissetoriais atendendo à profecia de Alfred Marshall ${ }^{7}$ : No capitalismo há apenas homens de negócios que exploram todos os negócios que podem. Exemplos tais como os mercados de café e de aparelhos celulares condicionam os mercados de vestuário e de alimentos.

Nas leituras simplificadas da economia de mercado - essencialmente de variações em curto prazo da demanda - ela aparece como constituída dos mercados de um grande número de produtos, quando na realidade são redes de mercadorias que estão interligadas por efeitos progressivos e regressivos de interdependência técnica, criados pelos sistemas de comercialização. Os principais cereais passaram a constituir redes de produtos e mesmo produtos tradicionais aparentemente artesanais como o inhame se tornaram matérias primas para agroquímica.

\section{TENDÊNCIAS E CONTRADIÇÕES DA QUESTÃO AGRÁRIA}

Há uma questão agrária moderna e outra de sempre, que não foi varrida pela modernidade. A de sempre demarca situações de poder e a moderna junta o poder econômico com o político. A questão agrária denomina a liberação da produção rural do domínio do comércio tal como em tempo disseram Chayanov (SILVA; STOLEKE, 1981) e vários outros. Há um verdadeiro abismo entre os progressos tecnológicos do mundo da produção em geral e em especial da produção rural e a pasmaceira ideológica que foi promovida pelo grande capital, ao separar o conhecimento científico daquele qualificado por Anthony Giddens (1995) de perito. Essa expressão infeliz foi adotada pelos órgãos internacionais que designam seus especialistas como peritos, isto é, profissionais que aplicam receitas consagradas sem cuidar muito de seus efeitos na vida social. No entanto, e por conta de inúmeros fracassos dessa política de peritos, tornou-se imperativo assumir um olhar avaliativo das contradições dos processos sociais da produção, isto é, aplicar à análise da produção o crivo da avaliação histórica tal como fizeram Samir

${ }^{7}$ Alfred Marshall, Industry and trade (1926). 
Amin (1977) e Christian Palloix (1972). O fundamento mais profundo desse problema de análise é a desumanização da economia, que opta pela relação entre capital e técnica em vez da relação entre capital e trabalho.

No mundo inteiro a questão agrária ressurgiu com toda força desde que se tornou evidente que o desmanche da União Soviética deveu-se, em grande parte, a uma política industrialista que não conseguiu superar os danos da segunda guerra mundial na produção de alimentos e que as doutrinas norte-americanas de trocar diesel por trigo revelaram-se tão autênticas como notas de três dólares. A versão chinesa do socialismo, dando prioridade a alimentos, veio ao encontro de dissidências no campo socialista mais ou menos ocidental, que clamavam por revisão dos fundamentos. Nesse sentido se destacam Samir Amin ${ }^{8}$ e os líderes da reforma agrária chilena, desde Jacques Chonchol (2003) aos socialistas do governo Allende. No Brasil a questão agrária surgia dos conflitos de terra que se acumularam desde a Marcha para o Oeste de Vargas e se desenfrearam com a invasão da Amazônia dos cerrados por grandes capitais desde a construção da BR-144 e da estrada Transamazônica. A versão romântica de ocupação dos cerrados por agricultores sulistas despossuídos foi suplantada pela verificação de compras de terras desde aviões e de uma maioria de proprietários ausentes. O mapa das migrações internas - do Nordeste para a Amazônia e do Nordeste e de Minas Gerais para o sudeste - marcavam um problema essencial da identidade brasileira, que o da mobilidade das bases rurais. $O$ discurso da simplificação, que reduziu a questão rural aos interesses dos grandes proprietários.

No atual ambiente contraditório da política econômica brasileira passa despercebido o fato que o fracasso em ofertar alimentos em quantidades e preços acessíveis à maioria, com a correspondente primazia à produção de mercadorias exportáveis, leva o país a uma crise sem precedentes já que esse problema de custo da vida hoje afeta a maioria dos $85 \%$ da população que mora nas cidades. A crise da alimentação evidencia a falha da política focalizada em agronegócios de exportação e mostra a necessidade de rever os fundamentos sociais e organizacionais da produção de alimentos. A própria Organização das Nações Unidas para a Alimentação e a Agricultura ( $F A O$, sigla do inglês Food and Agriculture Organization), que surgiu como broto de uma filosofia agrária tornou-se porta-voz de uma modernização que trata de relação entre produtores e bancos, mas ignora o papel controlador da comercialização. Seria preciso voltar aos ditames do estudo de José Carlos Mariategui (1928), que coincidiu com a perspectiva asiática do problema (ENGELBORGHS, 1981).

É onde entra a alternativa representada pela cooperativização da produção, que aparece como um modo de trabalho coletivo que preserva a independência individual e protege os produtores dos sistemas de comercialização. A longa história das associações rurais, cooperativas, ejidos, kibutz e outros, é a defesa dos produtores em sua dificuldade de conviver com a expansão do capital no meio rural. No Brasil se enfrenta com uma renovação e mecanização subsidiada da produção, mas é principalmente pelo controle de pequenos compradores. É o que Mariategui (1928) identificou no Peru como os gamonales e como funcionaram no Nordeste os compradores de fumo. O conflito agora é que as cooperativas representam uma valorização social dos produtores que confronta com o individualismo da grande propriedade e dos agronegócios, mas que elas precisam se atualizar como e enquanto instrumentos de luta cujo caminho é a qualificação dos produtores e criação de meios de comercialização.

\footnotetext{
${ }^{8}$ Samir Amin e Kostas Vergopoulos, A questão camponesa e o capitalismo (1977).
} 
Os problemas essenciais da questão agrária são antigos. Hesíodo, contemporâneo de Homero, escreveu Os trabalhos e os dias, em que contrasta o trabalho dos produtores com a ganância dos comerciantes. Desde então a maior trava da produção é a comercialização. Desde a ascensão do capital mercantil, os sistemas internacionais de comercialização determinaram a diferença básica entre agricultura como atividade conduzida pelos interesses do capital e produção agrária realizada por produtores. As diferenças entre camponeses e outros pequenos produtores passou a refletir condições de acumulação de experiência, modos de associação e capacidade de comercializar sua própria produção. A rachadura entre uma agricultura conduzida pelo pressuposto da comercialização individualizada e a da disputa com a comercialização conduzida pelos interesses dos produtores.

No capitalismo central, em que se ampliaram as distancias entre grandes e pequenos produtores, esse problema se aprofundou com a separação entre a comercialização das mercadorias de mercado geral e a dos inúmeros produtos que são mercadorias de mercados locais e regionais. Surgem contradições pela seletividade do consumo, quando os grupos de rendas médias e elevadas preferem produtos orgânicos, quando valorizam qualidade de vida antes que nível de consumo. Mas as tendências fundamentais continuam sendo dadas pela composição do consumo de massa controlado pelos sistemas de supermercados. $\mathrm{Na}$ atividade de dominação social do capitalismo periférico, os supermercados e os cerealistas desempenham um papel essencial de controle da produção e dos consumidores.

$\mathrm{Na}$ reorganização dos mercados mundiais depois da Segunda Guerra, passaram a pesar mais os interesses dos vendedores de equipamentos e de insumos agrícolas que vieram a influir na produção rural por meio de sua associação com os bancos. Da revolução verde ao projeto Aridas e à biotecnologia desenha-se uma trajetória de subordinação da pequena produção ao grande capital de complexos internacionais. Há um lado de tecnologia, promovido pelas grandes universidades, principalmente pelas norte-americanas, e um lado ideológico, conduzido pelos complexos agroindustriais, associado ao alargamento do setor improdutivo na economia, constituído de empresas de publicidade, marketing etc.

Construiu-se a ideologia da industrialização da agricultura representada por complexos agroindustriais, sob a qual há uma falsa disputa entre capital e trabalho, tal como entre pequenos produtores que operam à sombra de grandes empresas e produtores independentes. O fundamento do problema é o controle do mercado por parte $\mathrm{d}$ empresas agroindustriais e empresas vendedoras de insumos agrícolas e pelos agronegócios em geral que são a forma contemporânea da expansão do grande capital no meio rural. O conservadorismo tradicional do produtor rural ficou justificado pelo medo do controle dos bancos, tanto pelo endividamento como por orientações para subordinar a produção a sinais manipulados de mercado. Os supermercados passaram a serem determinantes indicativos de que produzir. Plantar matérias primas para a indústria de sucos e para iogurtes sem leite. Os produtores individuais ficaram mais fragilizados que antes com o recuo dos governos, em que o Brasil é exemplo, de retirar apoio aos produtores alegando razões de mercado. Enquanto os países ricos apoiam a agricultura, o Brasil, desde 1986 retirou apoio aos pequenos e médios agricultores.

O movimento geral de concentração do capital que se realiza a partir do bloco hegemônico da economia mundial, aprofunda desigualdades no centro e nas periferias do sistema produtivo e em diferentes níveis na esfera urbana e na rural. Com o estreitamento de opções de investimento tornam-se determinantes três processos interdependentes. Primeiro, que as grandes corporações precisam de oportunidades de aplicação que só podem ser conseguidas por meio de contratos de 
governo. Segundo, que o controle de tecnologia divide o mercado entre empresas que produzem tecnologias novas e empresas que compram tecnologias dominadas que já começam a operar como superadas. Terceiro, que o grande capital vê a produção rural como um departamento da produção industrial, sujeito às mesmas regras de redução de emprego e de taxa de salário. O grande capital investe na produção de mercadorias rurais mediante estratégias condicionadas por comercialização internacional.

A noção geral de periferia trazida por Raúl Prebisch (1986) deu lugar a uma teorização inovadora, mas que se tornou inadequada para refletir a variedade de economias periféricas, de grande e de pequeno porte, com maior ou menor aptidão comercial e de desenvolvimento tecnológico. Contrariando todas as teorias sobre periferias, a China tornou-se a segunda economia mundial e lidera em sistemas de comercio, utilizando combinações de soluções, copiando e modificando modelos de outros países em função de metas nacionais próprias ${ }^{9}$.

Os países periféricos como o Brasil são um componente essencial desse comércio mundial, onde, entretanto, ocupam um papel secundário, com certa complementaridade com os mais ricos como nos casos de carne, soja, cítricos. A produção de soja e de carne norte-americana é maior que a brasileira e a produção de carne de porco na China cresceram mais que a dos EUA e do Brasil. As mudanças de renda na China levaram a correspondentes mudanças na dieta dos chineses que passaram a consumir menos macarrão instantâneo e a comer mais proteínas e a substituírem arroz por batatas. As transações internacionais com proteínas encobrem estratégias nacionais de uso de água em que o Brasil funciona como barriga de aluguel para a exportação de água para a China. A produção dessas mercadorias não se confunde com a de alimentos, em que na economia mundial distingue-se o consumo de alimentos como bens salário das massas de trabalhadores do consumo de alimentos de alta qualidade que compõem o consumo das capas superiores de renda. A prioridade à produção de alimentos está alternativamente colocada como um problema de mercado ou como uma diretriz de planejamento.

Claro que as estratégias de produção do grande capital respondem a um aumento exponencial do consumo mundial, mas é de um consumo que cresce em poucos países, em contraponto com estagnação e empobrecimento, com o alargamento do subconsumo, com um componente irracional de desperdício, inclusive em países periféricos avançados como o Brasil. Os dados globais de consumo ocultam grandes diferenças de renda e também o fato que a renda pessoal disponível praticamente não cresce nos países do centro ${ }^{10}$. Mas o fundamental desta época é o movimento do grande capital, que gira em torno de algumas tecnologias selecionadas como a biotecnologia, a conservação de alimentos. $\mathrm{O}$

\footnotetext{
${ }^{9}$ A tese de Giovanni Arrighi (2008), de que os chineses copiam a economia clássica merece uma análise cuidadosa, desde descobrir as diferenças entre Adam Smith e David Ricardo até extrair leis fundamentais da formação de capital no capitalismo em que o cerne da questão é que o capital vai para onde o mercado se expande. A China controlou a expansão do mercado interno e em favor de sua política de exportação, mas introduziu uma guinada em favor da demanda interna, registrada desde o início da crise do capitalismo evidenciada em 2008. O novo projeto chinês de reativar a rota da seda construindo a maior rede de comércio do mundo vem a ser o maior projeto econômico do século.

${ }^{10}$ A descoberta de que a renda pessoal não cresce nos países do centro, isto é, Europa e países excolonialistas inclusive o Japão, é um dos principais sintomas de uma crise estrutural do sistema do capital cujo epicentro é a incerteza de que o sistema conseguirá formar capital suficiente para manter o capital já acumulado, ou que entra em uma contração que seria um freio secular do capital. A polêmica sobre a crise, que já foi tratada por Celso Furtado (1987) e István Mészáros (2004) volta ao picadeiro central quando os Estados Unidos se voltam para uma política protecionista e a economia mundial está condicionada pela aliança entre China e Rússia.
} 
mundo depende mais de bens intermediários como plásticos de alta densidade e cerâmicas de precisão, mas todos esses funcionam para atingir indiretamente os bens finais, onde estão os alimentos transformados e industrializados.

A revolução verde significou articulações entre mecanização e biotecnologia, como sementes híbridas. O capital foi em busca de terras baratas e a monoculturização está atrás da invasão de capitais internacionais no agro brasileiro. Subsequentes movimentos de modernização da produção rural ficaram subordinados a concentração do capital no controle de sementes e nos indicativos de produção de fruticultura como matéria prima industrial. O capital busca retornos sobre quantidades para o que opera com preços baixos de terra e redução do custo do trabalho. Na prática, terras exploradas sem reposição de nutrientes, mecanização e aproveitando o desemprego crônico do meio rural. As perdas de qualidade dos solos não registradas pelas contas nacionais e aparecem apenas em custos de nutrientes que refletem apenas cálculos de lucros.

A tensão agrária é o negativo dos agronegócios, que são a denominação geral do capital operacional no meio rural, onde finalmente registram-se os conflitos de interesses da esfera do capital. Seguindo uma escala de tecnologias encontramse agronegócios avançados e inclusive inovadores, que são parte de cadeias de investimento ao lado de uma maioria de agronegócios que depende basicamente de uma elevada taxa de exploração do trabalho, tal como na produção vitivinícola e na de café. O sistema de agronegócios depende de uma ampla e profunda exploração dos trabalhadores indefesos por sua ignorância. Logicamente, a expressão agronegócios encobre uma variedade de situações desde grandes complexos até negócios de escala municipal.

No Brasil o essencial é a não valorização da terra antes que sua desvalorização e é um movimento que aproveita a aliança entre a grande propriedade, representada na esfera política e o capital financeiro, que exerce um poder indireto, porém decisivo, sobre o sistema. O fator terra barata é a base de formas de exploração mecanizadas e de baixo efeito emprego, tal como a produção irrigada de açúcar sem pagamento de água. Esse é o bloco de poder essencialmente nacional que se coloca como interlocutor do capital internacional, administrando espaços de monopólio da economia nacional.

Nestas condições há uma renovação da questão agrária, que surge da combinação da expansão da grande produção mecanizada com as restrições de sobrevivência da pequena produção. O principal problema da sobrevivência da pequena produção é a centralização do capital na comercialização e a correspondente limitação da pequena produção a formas artesanais de comercialização. Os problemas de comercialização somam-se aos do bloqueio tecnológico devido a condições desfavoráveis de qualificação e dificuldade de acesso a financiamento.

Nesse contexto, a cooperativização é a única alternativa que permite combinar qualificação e liberdade de comercialização. Ao valorizar os trabalhadores, as cooperativas surgem como instrumento de progresso social. As cooperativas têm que ser planejadas para operar em condições desfavoráveis de concorrência, por isso com mais competência em suas atividades. O problema fundamental de conscientização dos pequenos produtores deve ser colocado como de sobrevivência em ambientes de mercado que estão controlados pela demanda concentrada dos supermercados e pelos sistemas locais de atravessadores. Mas é preciso cobrar competência das cooperativas. Elas não podem ser apenas associações de produtores, mas devem ser organizações capazes de operar em mercado e de se contraporem às vantagens acumuladas do lado do capital. O possível papel das cooperativas na produção rural terá hoje que tomar o componente de produção rural 
não agrícola - que vai do artesanato ao turismo rural - e que amplia as possibilidades de comercialização criativa. A perspectiva de um desenvolvimento diversificado da produção corresponde a uma concepção de cooperativa cuja essência é o próprio processo de trabalho e não as formas organizacionais. $O$ fundamento desse esforço terá que ser qualificação com motivação ideológica, pelo que focalizar em educação para o trabalho. Observa-se que o aspecto renovação da educação foi e tem sido fundamental em todos os processos sociais, revolucionários e reformistas, que valorizaram o papel das cooperativas no progresso social.

\section{CONDIÇÕES HISTÓRICAS DA PRODUÇÃO RURAL NO BRASIL}

Com esses antecedentes, torna-se necessário reconhecer o conjunto de condições externas e internas em que opera a produção rural no Brasil. As condições externas estão dadas pela composição da demanda internacional e as condições internas pelo preço do dinheiro e pela demanda local. Impõe-se substituir a análise setorial pela de circuitos de produção que estendem esses movimentos interativos entre as esferas financeira $e$ real e entre a produção dos estabelecimentos agropecuários e a produção industrial propriamente dita. Por exemplo, como situar a produção agroindustrial e a agroquímica. A irrigação mecânica é produção rural ou é uma atividade industrial no meio rural ? $^{11}$ Por extensão, procurar as ligações entre os planos macro e microeconômico em vez de trata-los como separados procurando um tratamento realista do tema.

Desde já, há uma diferença entre a maximização de lucros em monoculturas e a economia de estabelecimentos sociais, sejam eles de pequeno ou de médio porte, primeiro porque eles são necessariamente poli culturais e segundo, porque as combinações de produção de mercadorias sempre incluem componentes de consumo local. A produção social precisa repor o valor do trabalho, porque precisa manter seu próprio estoque de mão de obra enquanto a produção empresarial desvaloriza o trabalho como parte da valorização do capital, e segue políticas de substituição de trabalhadores por maquinaria.

Como a economia brasileira funciona como economia dependente de grandes mercados consumidores, especialmente da China e da Rússia, isto é, sem autonomia tecnológica, a produção rural empresarial é guiada por mercados internacionais e tem o mercado interno como residual. Essa condição faz com que a produção de alimentos seja secundaria para os grandes capitais ${ }^{\uparrow 2}$, ou que só seja reconhecida como exportação. Com a organização dos mercados urbanos conduzida pelos sistemas de supermercados, com a classificação dos produtos reduzindo sua diversidade sobre condicionantes de custos em escalas de produção, o mercado se divide entre bens salário de baixo valor por peso e bens de qualidade que atendem aos grupos médios e superiores de renda. Como esse segundo componente é constrangido pelos limites das classes medias, a produção rural de mercadorias responde ao mercado externo e a bens salário do mercado interno. $\mathrm{Na}$ prática significa que a produção de bens salário está regulada pela renda dos grupos de baixa renda, que está submetida a desemprego e incerteza.

\footnotetext{
${ }^{11}$ Assim como a análise industrial precisou reconhecer um setor de bens intermediários entre bens de consumo e bens de capital, que hoje inclui toda a petroquímica tornou-se igualmente necessário estabelecer um setor intermediário da produção rural, que inclui a agroindústria e a agroquímica. No Brasil hoje essa providencia é indispensável, porque a transformação agroindustrial atinge a maior parte dos produtos de consumo básico começando com a mandioca.

12 Esse pode ser um argumento que explique porque o Brasil importa feijão do México que tem $45 \%$ de território semiárido e da China que só tem $8 \%$ de seu território apto para agricultura. Também porque a produção de batatas no Brasil é quase toda de batatas de baixa qualidade.
} 
As especificidades vêm do curso da história em que o modo geral do escravismo se materializou em variedade de formas de vida desde a escravidão absoluta na produção de açúcar a formas menos opressivas na agropecuária e ao componente de extrativismo. Este abriu-se em parte ligado ao consumo e em parte definido pela exportação de madeiras de lei. Observe-se que a extração clandestina em larga escala de madeiras de lei, principalmente por empresas holandesas foi responsável da destruição da mata atlântica no sul da Bahia entre 1950 e 1970. Restos de troncos foram usados para demarcar fazendas de pecuária.

No movimento geral da urbanização a produção extrativa assume novas formas contribuindo com alimentos obtidos de modo primitivo para consumo urbano. É o caso da produção de moluscos, caranguejos e outros, extraídos dos manguezais das baías e incorporados nos sistemas de comercialização ${ }^{13}$.

A produção rural no Brasil tem fundamento no sistema colonial escravista e no escravismo pós-colonial, que deixaram marcas na grande propriedade e na subordinação dos trabalhadores. A grande produção rural instalou-se sobre a premissa de trabalho constrangido, escravo ou servo, e de terras invadidas, que sustentariam a premissa de terra barata ${ }^{14}$. Os componentes étnicos - exploração de índios e negros - foram argumentos operacionais utilizados pelo sistema de poder que não encobrem que o essencial é a exploração.

\section{PECULIARIDADES DO MODELO BRASILEIRO}

A formação da produção rural no Brasil partiu de uma apropriação violenta de terras e pessoas, a partir da subordinação e do massacre de índios e segundo a escravidão. O índio sempre foi mais barato que o negro e foi a verdadeira sustentação de uma produção que pouco modificou de suas formas técnicas iniciais. O princípio básico de uso de trabalho constrangido deu lugar a um autoritarismo incontrolado que encontrou formas sucedâneas da escravidão até os dias de hoje.

Torna-se claro que o atual sistema de produção rural no Brasil é uma aberração histórica, que atende apenas a um pequeno número de interesses e só alcança resultados econômicos nos ramos de maior exploração. Exploraram-se pobres de todo tipo, tal como, hoje se exploram paraguaios, bolivianos e outros. $O$ essencial é o sistema de dominação e não qual o dominado. A escravidão foi uma forma operacional transitória que foi substituída com vantagem pela exploração das populações locais de mestiços sem opção de fontes de renda. O fundamento de dominação é essencial para manter trabalho barato que é à base de terra barata. Assim, a partir de um mercado de terras de baixo preço instala-se um processo de tecnificação que desmonta o emprego rural. São processos que se desenvolvem a partir das grandes propriedades e realizam as opções de ocupação complementar dos trabalhadores incorporados em pequenas e medias propriedades. O anterior emprego rural com povoamento do campo foi substituído por moradia urbana favelizada dos trabalhadores rurais.

Surge novo cruzamento entre a questão agrária e a produção agrícola ou relativa ao fundamento agrário da questão agrícola. Esses deslocamentos entre o quadro social e o técnico acontecem em seguida de processos históricos pelos quais as regiões rurais de baixa renda fornecem força de trabalho para construção civil, comércio varejista, não só das regiões pauperizadas do semiárido, como de

\footnotetext{
${ }^{13}$ Estudos acadêmicos recentes identificam cerca de 4.000 mulheres "marisqueiras" na periferia de Salvador e indicativos de número equivalente ou superior de pessoas nessa atividade no litoral do Recôncavo.

${ }^{14}$ Projetos de expansão da produção de álcool no Nordeste na década de 1980 se apresentavam arguindo que seriam instalados em lugares onde não havia ninguém, isto é, que a população local era irrelevante.
} 
pequena produção dos estados do Leste e do Sul. Desse modo a força de trabalho disponível para a produção rural é sempre residual, principalmente composta dos que não puderam emigrar.

Será, portanto, necessário reavaliar o papel da produção rural frente às mudanças do mercado de bens de consumo e ao mercado de trabalho nas grandes cidades e nas regiões com grupos de rendas medias e superiores. Ressalta a diferença entre o papel da produção rural na sociedade econômica tradicional pouco urbanizada e o papel que desempenha em uma sociedade com quase $90 \%$ urbanizada e com uma proporção de mais de $50 \%$ de favelados e com um componente não inferior a $10 \%$ de excluídos da sociedade organizada. Assim, e considerando a importância social do componente de consumo local ou da produção artesanal para sobrevivência, é preciso considerar uma dualidade da produção rural, em que essa produção artesanal sustenta o exército de reserva da força de trabalho de produção rural empresarial. O sistema em seu conjunto se desloca levado pelo investimento no componente empresarial que reduz a absorção da força de trabalho gerada no meio rural.

\section{FORMAS TÉCNICAS E FORMAS SOCIAIS DE PRODUÇÃO}

O fundamento da produção rural é o plano de uso da terra, que pode assumir as formas puras de lavoura e de pecuária, ou de combinações agropecuárias, incluir a produção de madeira. O componente de extrativismo ocupa uma importante posição em grande parte da economia brasileira ${ }^{15}$. A produção de madeira pode passar do simples extrativismo à exploração programada de bosques plantados. Em uma perspectiva econômica essas opções podem ser manejadas por cálculos de retorno dos capitais, mas o peso de tradições, limitações culturais e financeiras, essas opções geralmente estão submetidas a uma inércia de decisões que se materializa na rigidez do sistema produtivo para se adaptar ao mercado ${ }^{16}$. Tal rigidez é a medida da irracionalidade do sistema.

Com essas referências, a produção rural pode ser decodificada como um conjunto de formas técnicas básicas que se desdobram em variantes, como por exemplo, a pecuária estabulada em diferentes tipos de confinamento de animais. $A$ perspectiva das formas técnicas é classificatória e pode ser útil para o planejamento regional, mas não explica porque algumas formas são escolhidas em vez de outras.

\section{A QUESTÃO AGRÁRIA}

O desmonte da discussão da questão agrária, ou de sua redução à agricultura decorre da subordinação da questão social à empresarial. As transformações da produção rural correspondem à atualização da questão agrária, em que a perda de capacidade de empregar e a maior mobilidade das pessoas determinam um ambiente social em que as pessoas procuram alternativas de condições de vida nas cidades. É a escala progressiva da favelização em cidades pequenas, medias e grandes e a precarização do emprego rural. Definem-se novas condições da questão agrária que precisa ser revisada.

\footnotetext{
15 O papel do extrativismo continuou sendo de componente atrasado da exploração no sistema do capital dependente, em que esses trabalhadores, em sua maioria mulheres, são explorados sustentando o consumo urbano.

${ }_{16}$ O cálculo econômico capitalista empresarial tende a reduzir ou ignorar o peso das tradições e dos argumentos culturais em geral, porém mesmo nos ambientes mais capitalistas há preconceitos e preferencias que não se explicam de outro modo, como por exemplo, as preferencias por determinadas leguminosas.
} 
A questão agrária é a principal herança da ocupação violenta das terras patrocinada pelo sistema colonial escravista e aperfeiçoada na economia escravista pós-colonial. O latifúndio foi principalmente introvertido, ou quase autárcico e as exportações ficaram por conta de extrativismo e mineração. O modelo primárioexportador capitalista só seria definido adiante pelo café e em menor escala pelo cacau. As exportações de açúcar que tiveram papel central no sistema colonial, só voltariam ao primeiro plano com o grande capital exportador e as grandes usinas desde a década de 1970. A questão agrária se precipita mediante sucessivos movimentos de expulsão de trabalhadores. Expandiu-se o problema da exploração indireta. Essa agora é representada pelo condicionamento de famílias de trabalhadores favelizados por emprego rural incerto e precário.

Descobre-se que no relativo ao campo rural é preciso trabalhar com o conceito de ocupação que é o único que dá conta de atividades estacionais e de ritmos de trabalho determinados pela natureza antes que por jornadas de trabalho análogas às da indústria. $O$ reconhecimento da especificidade do trabalho rural, registrado primeiro por Chayanov (SILVA; STOLEKE, 1981) torna-se o primeiro fundamento de uma análise da produção rural historicamente consistente.

Com a melhoria dos sistemas de transporte terrestres, aumentaram os movimentos de pessoas sobre distâncias maiores para trabalhar e passou a haver uma relação não explícita, mas essencial entre o esvaziamento demográfico dos espaços rurais e a favelização, com as correspondentes consequências do confinamento. Paralelamente, aumenta a violência principalmente contra os que moram isolados no campo, obrigando a novos modos de concentração nos povoados, tal como já se tornou uma regra nos estados nordestinos. Essa violência atinge pequenos e médios produtores, desvalorizando suas terras, induzindo que as vendam aos grandes proprietários, expulsando-os para povoados e para cidades de pequeno e médio porte. A violência se torna um aspecto essencial na vida rural que atinge as condições concretas da pequena e média produção ${ }^{17}$. O consequente despovoamento do campo cria a falsa imagem de eliminação de conflitos sociais rurais, mas que apenas mudam de forma.

\section{MODO DE ACUMULAÇÃO E PRODUÇÃO RURAL}

Na visão inicial de Marx a acumulação de capital surge do retorno de capital ao sistema produtivo, portanto, é um processo que resulta do retorno de uma pluralidade de capitais. Hoje, ao reconhecer o aprofundamento do sistema do capital com seu componente de incerteza, torna-se necessário registrar que esse retorno é sempre sobre bases técnicas diferentes e é incerto. Não há garantia alguma que a acumulação prossiga indefinidamente. Pelo contrário surge como tema dominante a incapacidade do sistema de gerar oportunidades de investimento suficientes para garantir a reprodução do capital acumulado (GAUDEMAR, 1977). A incerteza sobre a acumulação implica em questionar as bases sociais do capital, isto é a relação entre formação de capital e criação de emprego. A desigualdade inerente à acumulação na economia mundial põe os países periféricos em situação de dependência dos requisitos dos países mais ricos e na disjuntiva de encontrar novas alternativas para seu desenvolvimento. Como disse Celso Furtado (1987), trata-se de reverter tendências de subdesenvolvimento.

\footnotetext{
${ }^{17}$ A violência rural ainda é um tema pouco estudado no Brasil, onde ao lado da violência tradicional de fazendeiros com posseiros e índios, surgem novas formas de violência de tipo urbano, por quadrilhas e bandidos profissionais, com armamento e técnicas urbanas de assalto.
} 
Dadas inter-relações entre sistemas de tecnologia em grande e em pequena escala, mais e menos avançadas, o processo geral de acumulação surge da combinação de diferentes capitais, com variadas perspectivas de permanecerem em mercado. A acumulação engloba movimentos positivos e negativos por meio de ajustes e desajustes na reprodução dos capitais existentes. Como o progresso do sistema produtivo se dá com superação técnica de diversos de seus componentes, a acumulação é sempre um saldo positivo sobre um conjunto de ganhos e perdas. Destarte, as interações entre as formas de produção se realizam segundo a evolução dos mercados, com efeitos sobre a composição interna da produção no país e em suas relações externas. Essa é a determinação externa da produção rural, que opera segundo modos específicos de demanda, estabelecidos pelos sistemas de industrialização da produção primária. A produção de café solúvel soma-se à da industrialização do milho.

Tacitamente, supõe-se que a formação de preços depende primeiro da demanda externa, que é a que gera circulante autônomo da renda interna, sem atentar para o fato que é o consumo interno que determina pisos de preços dos bens salário que são alimentos de baixo valor por peso. Daí que a renda obtida de exportações aparece como vantagem frente à gerada pelo consumo interno. Mas essa é outra falácia já que as exportações são realizadas em grande parte na indústria e na mineração, por parte de empresas internacionais cuja renda vaza para o exterior e não contribuem para a acumulação de capital no país.

Nessa perspectiva global do processo, essa é a determinação externa que trata a demanda interna como residual. $\mathrm{Na}$ perspectiva das empresas as exportações são vantajosas porque permitem operar independente da capacidade de compra de setores sociais que tendem a se endividarem tangidos pelo desemprego. Por sua vez, na renda interna gerada pela produção rural há um componente localmente absorvido como produção de alimentos e outro engajado de modo subordinado na indústria de bens de consumo, voltado para a parte da população que não tem poupança. Significa que a produção rural no mercado interno está excluída da formação de capital.

Esse tem sido o princípio básico da exploração na modernização das economias dependentes. Nelas, a produção rural contribui para o movimento geral da acumulação, mas não acumula e deixa saldos negativos como esgotamento de solos e desemprego. A formação dos novos grandes complexos agrícolas e da pecuária no Brasil opera em articulação com os bancos e deriva seu poder de acumular para investimentos na esfera financeira. Esse processo é à base da reprimarização da economia nacional, cujo papel na economia mundial é externamente decidido.

\section{PERSPECTIVAS PREVISÍVEIS}

As propostas da chamada bancada ruralista no legislativo nacional apontam a aumento da exploração dos trabalhadores na produção rural brasileira com consequências imprevisíveis. As perspectivas da produção rural dependem de fatores econômicos e técnicos que regulam a demanda de produtos agrícolas e da pecuária e de fatores políticos da representação dos interesses dos capitais incorporados no setor. Os interesses dos trabalhadores, que abrangem os dos pequenos produtores, ficam fragilizados pela crescente dificuldade de associações representativas de seus interesses. São tendências do capital em geral que se especificam no momento atual da economia brasileira.

À luz das tendências de movimentos de capitais, de custos de financiamento e de concentração dos sistemas de comercialização, a produção rural 
tende a ficar determinada por interesses externos ao setor, ou que se separam por completo do que pode ser uma sociedade rural. No Brasil o controle da política rural pelos grandes proprietários, com sua representação legislativa coloca a questão rural em termos de exportações e de agronegócios. Essa visão de resultados desconhece o fato que as inter-relações entre o mundo rural e o urbano envolvem migrações nos espaços rurais de desempregados urbanos, assentamentos de comunidades, cooperativas e associações rurais. Movimentos de trabalhadores diaristas. São dados da complexidade do problema que tornam improcedentes as análises empiristas da questão rural.

\section{REFERÊNCIAS}

ABRAMOVAY, R. Paradigmas do capitalismo agrário em questão. São Paulo: Hucitec. 1998.

AMIN, S. La acumulación a escala mundial. México: Siglo XXI, 1977.

AMIN, S.; VERGOPOULOS, K. A questão camponesa e o capitalismo. Lisboa: A regra do jogo, 1978.

ARRIGHI, G. Adam Smith em Pequim, origens e fundamentos do século XXI. São Paulo: Boitempo, 2008.

BARAN, P. Teoria del crecimiento económico. México: Fondo de Cultura Económica, 1959.

CHAYANOV, A. V. Sobre a teoria dos sistemas econômicos não capitalistas. In: SILVA, J. G.; STOLEKE, V. A questão agrária. São Paulo: Brasiliense, 1981. p. 133-63.

CHONCHOL, J. La reforma agraria en América Latina, Buenos Aires: CLACSO, 2003.

CLARK, C. Conditions of economic progress. Londres: Mamillan, 1949.

ENGELBORGHS, M. La China rural. Barcelona: EF, 1981.

FOOD AND AGRICULTURE ORGANIZATION - FAO. Land, food and people. Roma: FAO, 1984.

FURTADO, C. Transformação e crise da economia mundial. São Paulo: Paz e Terra, 1987.

GAUDEMAR, J. Movilidad del trabajo y acumulación de capital. México: ERA, 1977.

GIDDENS, A. Modernização reflexiva. São Paulo: UNESP. 1995.

MARIATEGUI, J. M. Siete ensayos de interpretación de la realidad peruana. Lima: Minerva, 1928.

MARSHALL, A. Industry and trade. Londres, Macmillan, 1926. 
MÉSZÁROS, I. O poder da ideologia. São Paulo: Boitempo, 2004.

PALLOIX, C. A economia mundial capitalista. 2 vols. Lisboa: Estampa, 1972.

PEDRÃO, F. Refutação ao marginalismo. Salvador, Revista de Desenvolvimento Econômico, 2014.

PREBISCH, R. Capitalismo periférico: crisis y transformación. México: Fondo de Cultura Económica, 1987. 